\title{
La representación de la mujer en la revista SOHO de Ecuador
}

\author{
The representation of women in Ecuador's SOHO magazine
}

Carina Gisell López Cadena / Viviana Salomé Cisneros Endara*

\section{Introducción}

En la publicidad intervienen ciertas imágenes que pueden ser representadas de distintas formas dependiendo de cómo estas son manejadas por los medios de comunicación. Este artículo plantea el rol de la figura femenina desde el uso que se ha dado a su imagen en el mundo de la publicidad, donde ha sido utilizada como uno de los íconos más atrayentes para impactar a diversos tipos de espectadores. El rol que la mujer ha ocupado en los territorios de los imaginarios para la persuasión es uno de los ejes del trabajo, "Análisis de la representación del rol de la figura femenina dentro de la revista SOHO Ecuador". ${ }^{1}$

Desde una perspectiva de estudio cualitativo se realiza un análisis estético de la imagen y un estudio de la representación femenina de la mujer en esta publicación, con el propósito de comprender el uso de ésta en los mensajes de la revista, mensajes que son consumidos fundamentalmente por el público masculino.

Para entender el planteamiento de la revista, se revisaron conceptos como comunicación, publicidad y mujer, estereotipos, estética, entre otros; además del análisis teórico sobre la mujer-género que se manifiesta en este medio, la cual ha sido intervenida o manipulada para hacer de la imagen un elemento más llamativo, fijando con ello estereotipos de belleza que han sido aceptados por la sociedad y con los cuales muchas mujeres han sido afectadas por no alcanzar dichos parámetros estéticos.

Partiendo de la base de que las mujeres son tomadas como objetos, estas son impresionadas por los medios de comunicación, los cuales como estructura

\footnotetext{
* Comunicadoras Sociales, Carrera de Comunicación Social Universidad Politécnica Salesiana, Sede Quito.

1 Trabajo de Grado de la Carrera de Comunicación Social de la Universidad Politécnica Salesiana, Sede Quito, dirigido por el profesor David Jara. Este artículo es el resultado del trabajo de escritura científica con la docente Nelly Valbuena Bedoya.
} 
organizada se valen de parámetros de persuasión para intentar incidir sobre la audiencia consumidora de ideas, formas, figuras y comportamientos. El mensaje afecta al propio género que se auto regula a partir del modelo que se le establece.

La revista SOHO, "Prohibida para mujeres o solo para hombres" como dice su eslogan, deja flotando en el ámbito de la opinión pública la pregunta en relación con la representación del género ¿Cómo es posible que una revista que interviene el cuerpo femenino es prohibida para el mismo sexo?

Este artículo también aborda el interés publicitario a partir de un sistema tríadico; mensaje, audiencia y medios para comprender cómo es la representación de la estética del género dentro de la revista, mediante el análisis teórico de las imágenes y de una lectura crítica de las mismas.

\section{El género y el sexo en la perspectiva y el enfoque social de SOHO Ecuador}

Las determinaciones biológicas no pueden explicar la experiencia femenina, al vincularse al tema de género y descorporalizarlo, se refiere a un cuerpo como sustancia previa a la socialización, entonces la construcción del género es una construcción social que parte de que el cuerpo no es una cosa sino una situación que se desarrolla en el mismo cuerpo, el género es parte de dicha construcción social y cultural, dando especial énfasis al análisis denotativo y connotativo del sujeto.

Judith Butler toma la materialidad y la significación para comprender cómo el sexo fue excluido de la esfera pública, conjeturando un retorno indócil que incide radicalmente en lo simbólico, según el cual unos cuerpos importan más que otros, este poder social hace que el sujeto obtenga un valor y por lo tanto ejerza cierta influencia, produciendo que el sujeto se materialice (Butler, 2001).

SOHO fue la fuente de análisis de este trabajo por ser la revista que ha tomado el cuerpo femenino como un lenguaje en beneficio del medio, ya que el cuerpo de ésta, es constituido de un cuerpo sujeto a un cuerpo objeto y en sí la revista toma a las mujeres que en su opinión significan "más" que otras mujeres, teniendo presente que su contexto de consumo son los hombres de elite. 
La revista apareció por primera vez en Ecuador en el año 2000, con una circulación mensual desde el mes de mayo, caracterizándose como una publicación especializada para público masculino, abordando temas de intereses masculinos, con las colaboraciones de distinguidos personajes de la vida nacional, la política y las artes. Básicamente es una revista de entretenimiento y de consumo, el elemento o sección que sobresale es la sexualidad, pues cada mes exhibe una colección fotográfica con las "Mujeres más bonitas del país" que aparecen con la característica de estar "ligeras de ropa". Muchas de las portadas también son modelos colombianas que representan el "ideal" de belleza y de sexualidad.

Una de las características de $\mathrm{SOHO}$ es mostrar la desnudez de la mujer pues "la desnudez se engendró en la mente del espectador" (Berger, 1972). El desnudo está condicionado por la mirada; quién mira, cómo y desde dónde mira y cómo se comporta este cuerpo cuando es observado son preguntas para las que los editores de la publicación tienen respuestas. El cuerpo es un texto, se escribe dependiendo de lo que se quiera comunicar. Mencionar al espectador es especificar al hombre que mira con privilegio puesto que sobre él se establece una especie de norma de poder. Por lo que es necesario entender que la revista maneja el valor discursivo del cuerpo y la desnudes desde el punto de vista masculino.

Sin el espectador el cuerpo desnudo no es desnudo en sí mismo. El lugar donde se sitúa el hombre es el lugar del vestido, donde conserva sus prendas mientras mira el fruto de su presencia: la desnudez de la mujer. Y esta desnudez no es expuesta sin una pose específica, ya que también la forma de ocupación del espacio por la figura femenina depende de lo que se muestra. Es decir, existe una preocupación por parte de quien compone la imagen de cómo potencializar y exhibir de mejor manera este cuerpo para que provoque satisfacción y control en el espectador; refiriéndose a control como la manera en que el espectador mira y es él quien tiene a la vez el poder de ver y de saciar sus deseos.

Mencionar al espectador es especificar al hombre que mira con privilegio puesto que sobre él se establece una especie de norma de poder. Por lo que es necesario entender por qué el valor discursivo del cuerpo y la desnudez se manejan desde un punto de vista masculino. La masculinidad no se construye desde el contraste o la convivencia con la feminidad, sino desde la oposición de uno sobre el otro; rasgo característico que Francisca Luengo define como: "término etéreo de exclusión/inclusión". A partir de esta premisa lo masculino 
se establece como norma socialmente aceptada, relegando a todo lo que no lo sea a un nivel inferior como lo femenino propiamente dicho (Luengo, 2011).

El orden de lo masculino es algo que debe ser adoptado, pervivido y sobre todo respetado. "Una de estas expectativas está relacionada con la direccionalidad del deseo hacia las mujeres (...) Las extensiones homosexuales han sido equiparadas con "lo femenino" que se ha entendido históricamente como carencia" (Luengo, 2011). En consecuencia, todo "lo femenino", la mujer incluida, carece de valor por sí misma mientras no esté al servicio de dicha masculinidad, es decir, que el valor de lo femenino se adquiere en función de utilidad y reafirmación de poder.

Otra característica de $\mathrm{SOHO}$ es su representación dentro del espectador. Lo importante de la representación como parte cognitiva del sujeto es que ésta puede estar presente aún cuando el objeto se encuentre ausente, ya que el sentido que se suministra al este objeto, a través del lenguaje, le dota de significación constitutiva, construyendo así un sistema de comunicación que es capaz de expresar a los demás mediante un código común un mensaje específico.

El concepto que se construye a partir de la asimilación de un objeto, transcurre por una representación mental que permite que dicho objeto quede registrado de forma permanente en la memoria, de esta manera ya no es necesario advertir el objeto para reconocer cuando se lo nombra, cuando es de este y no de otro a quien se están refiriendo.

La revista $\mathrm{SOHO}$ ha manejado este proceso de representación hacia sus consumidores y el público en general; al hablar de la imagen y sin necesidad de haber visto la última publicación se puede visualizar qué imagen de mujer será la que ocupará la portada de la revista. El posicionamiento de un mensaje se convierte en parte del mundo simbólico de la persona cuando esta la hace parte de su mundo cognitivo.

¿Cómo es que el sentido siendo intrínseco al concepto y al lenguaje, sea capaz de un cambio ajeno a la trasformación indispensable de los otros dos? Porque el sentido no yace en el objeto, palabra, imagen y sonido, sino, que él lo produce y construye el sentido; el sentido atraviesa y se modifica, siendo capaz de convertir lo bello en su antítesis, la moda en anticuado, caro en barato, etcétera. Siguiendo esta característica, se mantiene donde está el sentido actual, 
vanguardista, siguiendo un concepto de belleza que va acorde al sentido de lo que culturalmente es naturalizado como bello.

¿Qué es lo que como revista quiere revelar? No obstante, la imagen mujer SOHO debe ser analizada semióticamente, esto quiere decir, estar al tanto de ¿Cuál es la interpretación que ésta proyecta? Tomando en cuenta que el objeto mujer, se parece a una mujer, pero no lo es, sino es un concepto imaginario o un nuevo contenido. Por ejemplo, se ha visualizado en las redes sociales (Facebook y Twitter) que la imagen es muy importante para la revista pues es el ancla que adquiere para aumentar su número de "lectores" e incluso para preservarlos. Por tal motivo se toman el tiempo de preguntar al espectador ¿Cuál es la mujer que ellos quisieran ver en SOHO? o ¿Cuál es la mujer que más inspira sexo?

Esta mujer que visualmente ya es un símbolo mediático, representa y determina una imagen pública, igualmente ella está en condiciones de disfrutar este peso mediático. La revista determina nuevos paradigmas de representación. En este punto, la mujer-sujeto, es reemplazada para representar este concepto imaginario de mujer $\mathrm{SOHO}$ asociada a la elite y al concepto de belleza que propone la publicación.

Los lectores de la revista, se hacen conocer por las repuestas a las preguntas que la revista les hace a través de las redes sociales como Twiter, @ecuador2012, situando estadísticamente a la actriz, modelo y presentadora de televisión ecuatoriana Erika Vélez como la primera opción de respuesta, así como también se nombra a la presentadora de televisión y modelo Cinthya Coppiano. Posteriormente aparecen la actriz y modelo Flor María Palomeque y la modelo y presentadora de televisión Mirely Barzola. La imagen de estas mujeres tiene una connotación asociada a la palabra belleza, creando una imagen consecutiva de memoria en donde el sujeto cuando escucha la palabra mujer, almacena en su retentiva un icono o una percepción de tal imagen ¿Qué signo, significado, símbolo y código deben tener tales mujeres para pertenecer al grupo de las mujeres virtuales más bellas? Todos estos conceptos desarrollan y forman un contexto y un marco teórico, en este caso, la representación de la figura femenina en la revista (Eco, 1968).

Si bien es cierto, este documento está enfocado a analizar la imagen de la portada de la mujer que la revista SOHO Ecuador presenta, también se creyó 
necesario hacer un paréntesis en la exclusividad de tomar sólo las revistas de la edición Ecuador, mostrando este ejemplo claro y actual de lo que en teoría se manifiesta y que en el contexto actual se corrobora.

La portada adicional tomada como referencia para el análisis es la del mes de marzo de 2012 que provocó una gran discusión acerca de lo que una imagen puede llegar a representar, incluso se llegó a cuestionar el racismo, la exclusión, la demanda, el engrandecimiento de la raza negra; todo esto tan sólo con una fotografía que puesta en análisis es más que una imagen de mujeres bellas y que ha sido una de las portadas más conflictivas para la revista por utilizar modelos negras con dos mujeres mestizas al fondo representando a empleadas del servicio doméstico. ${ }^{2}$ Lo que se quiere mostrar, es que a pesar que SOHO critica a la fotografía de la revista "Hola" no dejan de lado el erotismo de la mujer. Puesto que al reflejar a las mujeres afro descendientes desnudas, se mantiene esto de que la revista está enfocada al mercado.

La revista manipula, cambia la percepción de lo que habitualmente se piensa, construye memoria y pone en disposición cosas que se creían ausentes. El objeto de mujer -que siempre será un sujeto en contextos como los latinoamericanos- al ser ya una imagen convertida en lienzo y coloreada con tonos especiales, construye un nuevo saber y cambia la percepción ontológica, convirtiéndose un espectáculo comunicativo.

Este significado no varía hasta que el sujeto consumidor hace suya la imagen y la desencaja en un discurso, es lo que Michel Foucault describe como formaciones discursivas o modos de representaciones (Foucault, 1970).

La mirada es la pauta para la creación de un rol que se impone a partir de esa mirada; lo que se distingue y desde donde se distingue no es arbitrario, sino

2 Esta polémica se inició cuando la Revista SOHO de Colombia respondió a la portada de la revista española Hola. Tanto la portada de SOHO (Colombia) y Hola (España) causó controversia. En su edición de marzo, la revista SOHO publicó en su portada a cuatro modelos negras en primer plano y detrás dos empleadas domésticas mestizas. La publicación fue una respuesta, según los editores de la revista, a una fotografía que la revista española publicó en diciembre pasado en la que aparecen cuatro mujeres, integrantes de una familia élite de la ciudad de Cali y detrás de ellas dos empleadas negras. 
más bien es una elaboración compleja que condiciona al objeto que se mira en cómo se lo mirará. De esta manera dentro de la revista la mujer se convierte en el objeto del espectador y en el objeto para sí misma, puesto que tal como describe el autor, la mujer se convierte en una de las primeras en hacer inherente a sí misma la condición de ser observada, generando comportamientos, posturas, formas que le permitan ser aceptada por el entorno que la evalúa.

Antes, culturalmente la mujer, manejada por su sexo, era obligada socialmente a desarrollarse o desenvolverse en un ámbito de dominio del sexo opuesto (el varón), en el que el hecho de nacer con el sexo mujer era sinónimo de represión, inferioridad y abuso. La mujer no podía elegir, sus funciones eran delimitadas, ser esposa y madre y durante largos siglos, correspondió al destino femenino, ser moldeada como un ser inferior, excluida de las decisiones públicas y estudios superiores. Ahora, las mujeres rompen los esquemas que les fueron impuestos. Pretende liberarse sobre todo del matrimonio y la maternidad. Los grupos de feministas y defensoras del concepto de género han logrado romper las normas "patriarcales", transformar los hábitos, las costumbres y las concepciones, tanto en el campo doméstico como en el laboral. Sin embargo, los medios siguen modelando la imagen de la mujer para fines publicitarios.

Estas características pueden encontrarse en mujeres que priorizan la realización de sus propios planes y no anteponen a ellos la dedicación total a los demás (sea esta la familia, la pareja o los hijos). Se preocupan de sí mismas, en su economía, su cuerpo y sobre todo en el discurso sobre el cuerpo. Es decir, la imagen corporal dentro de los ámbitos sociales, (modales) para saber cómo, por qué y qué expresan cuando son miradas. Por eso, las mujeres que son capaces de articular la labor de madre con el trabajo; y a su vez presentan una mayor preocupación por su desarrollo personal, podrían ser consideradas como 'disruptivas' de la normatividad y la organización simbólica en lo doméstico, lo comunitario y lo social.

El cuerpo es un discurso, éste debe portarse como quiere que lo vean, en este caso son el erotismo cultural del género, la representación de una mente fabricada, es la idealización del sexo de la feminidad y una construcción de la preforma mujer.

La mujer SOHO tiende a fijar con detalle su comportamiento frente a los demás, en especial frente al género opuesto, ya que es el hombre el que observa 
a la mujer, la examina antes de establecer una relación con ella. Si se fija que el público masculino sea el consumidor masivo del producto, se establece que quien mira mayoritariamente a la mujer es el hombre, de esta forma la mirada masculina examina a la mujer como producto. Por ello, la imagen de la mujer en la revista deberá ir acorde a sus exigencias como consumidor potencial.

¿Cómo el cuerpo proyecta y qué es lo que proyecta? Entendemos al cuerpo como un transmisor que es capaz de contener en sí mismo lo objetivo y lo subjetivo, lo que él refleja es también ese mundo interno que se proyecta hacia los límites exteriores del mismo.

La construcción del cuerpo en los contextos viene a situarse bajo una mirada discursiva y de poder -tal como lo expresa Foucault- que fija los límites de qué es y qué no es un cuerpo pues este construye su materialidad a partir de dicha normativa. La cuestión es que, al referirse a la normativa y cultura al mismo tiempo, se establecen parámetros que hacen que el género tal como lo dice Foucault: "absorba y desplace al 'sexo' remplazando el cuerpo natural por este cuerpo social". Por eso es necesario entender que la materialización es en sí misma parte de la materialidad del sexo y que en esto consisten las acciones performativas.

\section{La mujer SOHO y su discurso representativo en los medios pu- blicitarios}

Existen procesos de construcción de sentidos mediante los cuales se da a entender una idea o se refuerza otra. Esto es a lo que la semiótica considera como el cambio de los sentidos. La repetición de lo diferente, dista de tratar de ser una memoria como ocurre con el ritual y el mito, que nacen de una repetición de la semejanza; aquí la repetición se enfoca en el presente. Barthes explica el registro de figuras repetitivas como el "amor" (Barthes, 2003); esta forma también se puede utilizar para hablar de la repetición en el mensaje de la belleza a nivel semiótico dentro del lenguaje discursivo. "Hablar, y con mayor razón todavía circular, no es comunicar, como suele repetírselo en el lenguaje común y corriente, es someter: toda lengua es un sometimiento generalizado" 
(Hall, 1997), debido a que los límites del mundo son puestos por el lenguaje, hablando de una relación de poder intrínseca al discurso.

El ser humano es capaz de manejar emotividades y sobre todo de comunicar mensajes utilizando cada elemento de sí mismo como un código, por eso se justifica el aforismo: "como la lengua se hace carne".

El concepto de la mujer es un sistema abstracto donde la imagen sufre cambios antes de ser exhibida, adquiriendo una representación de lo que sería una mujer para el hombre de élite. La mujer es un símbolo, ésta significa lo que representa a un sujeto "mujer", que atrae por su imagen de belleza bajo el concepto "greco-romano", en la que operaran las convicciones estéticas que hoy existen y que consideramos bajo el parámetro de "ideal". En este caso la revista muestra a un estereotipo de mujer bella virtual, cambiando el objeto imagen de mujer a un sujeto dividido entre lo que es y lo que representa. En otras palabras el sujeto mujer es un constructo social.

A partir de esta construcción de la mujer "ideal", no sólo se fragmenta lo que es y lo que se representa sino la identidad misma del sujeto, es decir, el momento en que el sujeto es parte de la mediación hasta convertirse en representación, la fragmentación se convierte en requisito para la reconstrucción y la repetición.

El modelo original se diluye en la repetición, se entiende que todo mensaje es una mediación, pero lo que se recalca aquí es que un mensaje que se distribuye en masa, como es el caso de la imagen de la mujer en la revista $\mathrm{SOHO}$ Ecuador gana otros niveles de significado, con la condición de perder la esencia misma del ser, conduciendo a una crisis de identidad y cayendo en la era de la simulación.

En la publicidad la persuasión tiene como finalidad inducir al receptor a través de un objeto, centro o argumento racional y provocar en él una (re)acción. La manera de persuadir de la revista $\mathrm{SOHO}$ a sus receptores hombres, es a través de la portada, esto no quiere decir que no aportan créditos las demás paginas (reportajes, editoriales y crónicas), pero la construcción de este símbolo es la asociación corporal. Simular lo real bajo este modelo de repetición naturaliza esta nueva forma de sometimiento.

Se puede decir entonces que, la mujer solo puede llegar a ser asimilada como discurso, si antes es asimilada como concepto (Mujer-belleza) para ser 
aceptada como tal. A la sazón, dentro de la estructura del lenguaje, el discurso es el nivel máximo de la comunicación y el concepto, el punto del que parte para formarse en sí.

La revista trabaja a partir de estereotipos y representaciones pero en el tratamiento de su lenguaje compone cierta imagen de mujer utilizando como principal herramienta la fotografía, pero no una fotografía convencional, sino una foto compuesta que tiene como ley distanciar al sujeto de sí mismo y convertirlo en objeto de consumo, ya que la figura de la mujer es expuesta frente a un aparato que captura una imagen dejando de ser la "modelo" y convirtiéndose en la imagen visual representada de la misma.

La mujer es un existente a quien se le pide se haga objeto; como sujeto, tiene una sensualidad agresiva que no se satisface con el cuerpo masculino, de donde nace los conflictos que su erotismo debe superar (...) pero ese "naturalismo" es ordenado por un interés social más o menos bien entendido (Beauvoir, 1949).

Ante el marco del actual fetichismo de la imagen, el imaginario de lo femenino que presenta la publicidad no deja de ilustrar las contradicciones que descansan en los planteamientos culturales de cada sociedad. Es decir, por una parte, se defiende con la teoría un compromiso con la vida, la libertad y la búsqueda de la felicidad, así como el respeto a todos los seres humanos sin distinción de sexo, raza o condición; por otra parte, la publicidad, como ocurre en otras esferas, comercializa imágenes que suscitan un condicionamiento social y educacional en donde se potencia la diferenciación y el sexismo. Las imágenes con las que la publicidad ha definido a la mujer, en un mundo íntegramente mediatizado, lleno de productos absolutamente impersonales, hechos a máquina y no tocados por la mano humana, ha sido la conversión de la mujer en un signo ritmado por el reclamo y la promoción, lo cual han remarcado su identidad sexual.

La imagen del género femenino no escapa a esta regla y se convierte en espejo de sueños en los que se pretende atrapar al observador. En muchas ocasiones se trata simplemente de proporcionar una nueva envoltura. Las fotos retrato que se encuentran en $\mathrm{SOHO}$, edifican el valor de una fotografía fetichista o publicitaria: la seducción no solamente de la mujer, sino la acción misma de seducir por medio de las imágenes y la atracción de los reportajes van configurando una composición estratégica para el consumo. Por lo que no es relevante 
si la fotografía goza de los anteriores elementos barthesianos, lo significativo de la foto, en este caso, es vender el cuerpo, la imagen sobresaliente que atraiga de manera irreductible al espectador.

Las fotografías en SOHO son inconfundibles, la sensualidad y la carga erótica, son retratadas con un halo de donde los distintos fotógrafos, detrás de las cámaras hacen las veces de un mirón que contempla a la mujer como un objeto fetiche. Más que hablar de las fotografías y de la mujer, se tomará en cuenta que estas son importantes por el hecho de que la imagen del sujeto ya es reconocida. Por ello, se reseña la idea de fetichismo, en el que cualquier hombre se imagina observar el cuerpo de Érica Vélez al desnudo, afirmamos esto pues es importante la imagen que ella ha construido y la fotografía, en este caso el retrato, tiene el valor por las características que le otorga el fotógrafo, convirtiéndose en el "voyeur" que fotografía lo que a otros les gustaría mirar.

\section{Conclusiones}

En torno a los puntos problematizados en este documento, es menester dejar en claro que este trabajo de ningún modo se clausura, sino que por el contrario, deja abiertas algunas cuestiones que pueden ser problematizadas desde otras disciplinas como la Antropología y Sociología del cuerpo; asimismo en el horizonte de las Representaciones corporales y los Estudios Culturales. Por lo que estas consideraciones son provisionales, pues no caen en el absolutismo de las premisas del positivismo en ciencias sociales, sino que servirán en un futuro próximo para dinamizar ciertos debates sobre representación, comunicación y corporalidad. En ese marco se asevera que:

La representación es el sistema fundamental de la comunicación que permite que el mundo sea inteligible al ser humano, logrando que el lenguaje tenga un valor cognitivo y de significación. La representación de la mujer en la revista SOHO establece un lenguaje editorial propio que resalta a la representación de la belleza femenina y la sensualidad como bases de su lenguaje visual; la mujer como símbolo de una revista de "elite".

Dentro de la comunicación visual, son las imágenes y los signos visuales los que hacen referencia a las cosas que representan y le otorgan una serie de 
significaciones sociales. La imagen de la mujer dentro de la revista se concibe como un cuerpo fragmentado; un sujeto-objeto como lo denomina Barthes, al convertirse en una proyección de la realidad que usa como medio el soporte fotográfico y desde un punto de vista específico, convirtiéndose en un fin en sí mismo: un retrato.

El objetivo de la imagen es seducir al espectador a partir de la mirada. La mujer es colocada como un símbolo sexual que atrae, que significa belleza. Se mira a la figura femenina como el gancho del producto.

La publicidad es un medio de transmisión de un mensaje específico, que en el caso de la publicidad visual se convierte en el mensaje en sí mismo. La mujer es parte del código visual que compone la fotografía publicitaria de dicha publicación y es sobre la cual se constituye el valor semiótico de la imagen.

El género se diferencia del sexo, ya que este es una construcción social que posiciona tanto al hombre como a la mujer en sitios discursivos distintos. El género de la mujer se lo entiende a partir de una estructura social y cultural; el género femenino es un género que deviene en una mujer-objeto de deseo subyugación ante el género masculino. El rol de la figura femenina dentro de SOHO es fundamentalmente el cuerpo; y este como objeto a ser descubierto con una mirada publicitaria enfocada al público mayoritariamente masculino.

El cuerpo de la mujer es una construcción social que establece cual es su posición dentro del discurso de poder, en el que prevalece una visión masculina. Según Simone de Beauvoir esta es la premisa que divide al sexo del género y que formula una larga lista teórica de cuál es la función que cumple la mujer frente a esas distinciones. Para que exista una construcción de género es necesario que exista una mirada, pues gracias a esta se constituye la otredad.

La fotografía es la principal herramienta de construcción del lenguaje de y en sí de la publicidad actual. La fotografía construye miradas, permite ver y ser visto. La mujer existe a partir del lente que la captura fotográficamente. Desde donde se mira un cuerpo, es desde donde va a ser leído. La mujer es leída desde el punto de vista del fotógrafo, desde la propuesta editorial, desde la composición fotográfica.

El recurso más efectivo en la composición fotográfica de la revista es el desnudo. La piel como extensión de la sexualidad, utilizada como una herramienta sensorial capaz de atraer la mirada del espectador atento a lo que ve y a 
lo que la modelo oculta pero que insinúa. Por eso es que: como afirma Ardévol una fotografía no es más que un trozo de papel, si no hay una mirada que se asome a la misma. La fotografía nos habla de la propia mirada.

Con el análisis denotativo y connotativo de las imágenes se puede concluir que la publicidad moldea al sujeto cargado de elementos estéticos, símbolos y sentidos bajo su interés, para persuadir y complacer al consumidor de elite; en este caso al género masculino, concibiendo que la revista tome un mayor valor y que sus mujeres cumpliendo con tales características conviertan a este medio impreso como un objeto persuasivo para su consumo.

El sistema de representaciones y las formas de ver la figura femenina como un cuerpo semiótico que adquiere significados dentro de un sistema de comunicativo visual enfocado a la publicidad y el consumo, ha permitido delinear un horizonte de estudio infinito; siendo el objetivo fijarse en el análisis discursivo, fotográfico, semiótico del rol de la mujer dentro de la revista, se ha visto a lo largo del análisis de la investigación de esta tesis que existen muchos otros caminos teóricos que enriquecerían temas relacionados. Es necesario entender que los temas de investigación que parten de la construcción de perspectivas de realidad, como la representación, nacen todos a partir de la construcción de los sentidos, de la interacción simbólica y cognitiva que tiene distintos niveles y puede ser analizada a partir de múltiples puntos de vista. Sería recomendable que se desarrolle un análisis del rol de la mujer y de su presencia como imagen colectiva en la construcción de representaciones desde un punto de vista de la psicología; esta tesis se basa en el análisis del estereotipo de la mujer, que a diferencia del arquetipo, el cual estudia el modelo original, estudia la imagen o concepto aceptado comúnmente por la sociedad o por un grupo determinado de individuos. Es por esto que fortalecería este tema si en futuras investigaciones se tomara en cuenta también una noción junguiana de la construcción de la imagen representada de la mujer como un arquetipo. Para Jung, en la construcción de sentido está como principio el "inconsciente colectivo" el cual se conforma a partir de las teorías del inconsciente de Freud y de las representaciones colectivas de Durkheim (Jung, 1984).

La profundización de los aportes académicos de estos autores, en especial de Karl Jung, enriquecerían un estudio que abriría más puertas al entendimiento del tema, ya que el mismo Jung establece que la construcción de arquetipos 
permite entender cómo formas preconcebidas moldean el comportamiento de las personas. Entonces se podría desarrollar un sentido de codependencia más profundamente tratado entre la imagen de la mujer y lo que esta produce en el comportamiento de la sociedad.

En esta tesis se formula al cuerpo de la mujer como un estímulo; como un sujeto-objeto, parte de un sistema publicitario visual que se convierte en el enganche del consumo de un medio determinado. Sacando a la representación de esta bajo el enfoque publicitario y colocándola como la construcción de una imagen gestora de un comportamiento inconsciente en la sociedad, sería posible develar no sólo las dimensiones del poder de las imágenes, sino también las dimensiones en las que la sociedad actual se conforma como mundos de significados y a qué nuevos arquetipos obedecen.

Teniendo en cuenta que los arquetipos tienen una función compensatoria y obedeciendo a la teoría de Jung: la compensación y el equilibrio de los opuestos, sería enriquecedor conocer cómo es que la sociedad en su psicología se imagina a sí misma en el nivel consiente y cómo ésta se construye así misma en su psicología. Entender qué es lo que la sociedad percibe como belleza, sería entender cómo se ve a ella misma: si fea, gorda, flaca, etcétera y con base en qué principios colectivos no consientes lo hace, además del por qué toma tales o cuales referentes para posicionarlos arquetípicamente como motores de comportamiento. Conocer los sueños de una sociedad y de cómo se encuentra a partir de los sueños, construye imágenes representadas de cómo se vería a sí misma en un mundo ideal.

Ver a la sociedad como un cuerpo, como un individuo, permite no sólo conocer lo que mira sino también como funciona su sentido cognitivo e inconsciente en relación a lo que observa, es decir, entender la imagen ya no desde quién la produce sino centrarse en quien la percibe como uniformidad social permitirá conocer el poder de la comunicación en la sociedad y el poder de los mensajes como flujo constante en los entornos sociales y culturales. 


\section{Bibliografía}

BARTHES, Roland

2003 Ensayos Críticos. Editorial Seix Barral. Los tres mundos.

http://estudiosliterariosunrn.files.wordpress.com/2010/08/barthes-rolandensayos-criticos.pdf

BARTHES, Roland

1993 La aventura semiológica. Ediciones Paidos. España.

BEAUVOIR, Simone

1949 El segundo sexo.

http://es.scribd.com/doc/23877165/Beauvoir-Simone-de-El-segundo-sexo-1949

BERGER John

1972 Modos de ver. Edición inglesa.

http://paralelotrac.files.wordpress.com/2011/05/modos-de-ver-john-berger. pdf

BOTLER Judith

2001 El género en disputa. El feminismo y la subversión de la identidad. Editorial Paidos.

ECO, Umberto

1968 La Estructura Ausente. Introducción a la Semiótica. Editorial Lumen. http://www.upv.es/laboluz/leer/books/eco_estructura_ausente.pdf

FOUCAULT, Michel

1970 La arqueología del saber. Siglo XXI Editores.

http://investigacion.politicas.unam.mx/teoriasociologicaparatodos/pdf/

Contempor\%E1nea/Foucault\%20-\%20La\%20arqueolog\%EDa\%20del\%20 saber.pdf

HALL Stuart

1997 El trabajo de la representación. Sage Publications. Londres.

http://metamentaldoc.com/14_El_trabajo_de_la_representacion_Stuart

JUNG, Carl G Hall.pdf

1984 Arquetipos e inconsciente colectivo.Traducción de Miguel Murmis. 2da Edición. Barcelona. Paidós. Fragmentos.

\section{LUENGO BAEZA. Francisca}

2011 Masculinidades no dominantes: Una etnografía virtual. FLACSO. Quito. 